\title{
Modified track shoes and their effect on the EMG activity of calf muscles
}

\author{
Marlon Greensword, *Fereydoun Aghazadeh, and Saif Al-Qaisi \\ Department of Construction Management and Industrial Engineering, 3128 Patrick F. Taylor Hall, Louisiana \\ State University Baton Rouge, LA, 70803, USA
}

\begin{abstract}
Although track and field spike shoes are crafted for runners, these shoes are not designed for regular walking. With such shoes, runners may eventually encounter serious chronic injuries such as plantar fasciitis, shin splints, achilles tendinitis, chondromalacia, and iliotibial band syndrome. To address this problem, a modified spike shoe was tested and compared to a regular spike shoe. The modification consists of adding a removable heel to the shoe sole in order to reduce the flexion of the foot and properly level the foot for walking. Nine healthy participants performed walking drills at 2 and $3 \mathrm{mph}$, using the original and the modified shoes. Electromyography (EMG) measurements were used to evaluate muscle activities. Participants also rated their discomfort on a 0-10 scale. Results show that the use of modified shoes resulted in a reduction of $22 \%$ and $24.25 \%$ EMG activity for the tibialis and gastrocnemius muscles, respectively. Comfort ratings increased by an average of 2.7 , 2.6, 3.9, and 4.2 points at the knees, calves, ankles, and feet, respectively.
\end{abstract}

Keywords: Running injuries, sports ergonomic, running gear, EMG, track and field

\section{Introduction}

The most common injuries among track runners are plantar fasciitis, shin splint (tibial stress syndrome), and Achilles tendinitis. The latter originates primarily from using inappropriate footwear [1].

Track athletes traditionally wear spike shoes designed exclusively for running during competition and training. Track athletes wear spikes at a minimum of three hours a day and four days a week. The athletes tend to develop problems within two months to a year in the legs, lower back, tibia, metatarsals, and patella [17,18]. Approximately $84 \%$ of injuries among runners occur on the tibia (shin) area, with $13 \%$ of the injuries linked to the Achilles tendon [11].

This project examines the feasibility of using an innovative track spike shoe for running. The modified shoes were fitted with a removable heel, making them adaptable to both running and walking. ${ }^{1}$

\section{Background}

Different movements characterize different walking and running techniques [7]. Inversion is a movement of the soles medially at the intertarsal joints. Eversion is a lateral movement of the soles at the intertarsal joints. Dorsiflexion (DF) refers to the bending of the foot at the ankle or talocrural joint in the direction of the dorsum. DF occurs when one stands on one's heels. Plantarflexion (PF) involves bending of the foot at the ankle joint in the direction of the plantar or inferior surface, as when standing on your toes. In other words, DF is true flexion, whereas plantar flexion is true extension.

The ankle-foot walking process can be divided into two major stages: stance and swing [21]. Stance, which constitutes the majority of the walking process (about 60\%), is made up of three phases:

*Corresponding auther. Email: aghazadeh@1su.edu 
1. Controlled PF: begins at heel-strike and ends at foot-flat. During this phase, the heel and forefoot make initial ground contact.

2. Controlled dorsiflexion (CD): begins at foot-flat and continues until the ankle reaches maximum DF. During $\mathrm{CD}$, the ankle stores the elastic energy needed to propel the body upward and forward during the next phase.

3. Powered plantarflexion: begins at maximum DF and ends at toe-off. During this phase, energy is supplied, in addition to the spring energy stored from the previous phase, to achieve the high PF power during late stance.

Swing is the second stage of the walking process that separates each stance, starting at toe-off and ending at heel strike. During swing, the foot is lifted to proceed to actual geographic locomotion.

The classic spike shoes are designed in such a way to assist athletes to run on their toes in PF mode and improve running performance. Since the shoes were designed specifically for running, problems arise when they are used for walking. During walking, the shoe shape makes the athletes walk primarily on their heels in DF mode. This foot posture exerts substantial pressure on the tibia and gastrocnemius that can eventually injure the Achilles' tendon.

Furthermore, extreme or repetitive DF may lead to direct trauma as well as the formation of osteophytes on the anterior edge of the distal tibia called anterior bony ankle impingement [4]. This can result in painful symptoms and adversely affect the athlete's performance. One intervention proposed to reduce the DF from using spike shoes is the to add an internal or external heel lift to the shoes[4].

Several gait determinants differentiate normal and pathological walking [8]. An inefficient, pathological gait pattern is characterized by numerous lateral and vertical excursions in the body's center of gravity. Walking in spike shoes without a heel challenges the ankle to maintain the balance of the body; thus creating a vertical excursion in the center of gravity, as pressure is exerted on the TA and the Achilles tendon. When compared to the normal human gait pattern, walking in heelless spike shoes qualifies as a pathological gait, and requires correction.

A study of the lower extremities muscles' activity as a response to ground reaction forces showed that the ratio of mean pre-activation intensities to post-impact intensities was $96 \%$ in the TA and $48 \%$ in the gastrocnemius [9]. Therefore, conditions in which the impact to the ground is increased, such as walking in heelless spike shoes, implicate a more intense muscle activity in the gastrocnemius and TA muscles. However, in the case of spike shoes with removable heels, the shoes may absorb some of the impact forces, and consequently reduce the muscle activity.

Extrinsic foot muscles are the "muscles that insert on the foot but originate proximal to the foot" [12,13]. The TA muscle is an inverter of the foot. Measurements of extrinsic foot muscle impact [2,15], indicated some degree of tibialis "overuse" during running among track-and-field athletes. If the foot does not have the needed support, such as that provided by a heel, there remains a failure to relieve and rest this muscle after exercise, since walking demands effort from this muscle. The TA then exerts a controlling role on the heel stress, because TA, "restrains rearfoot PF from heel contact to $10 \%$ stance and eversion between $10 \%$ stance and footflat" during walking [2]. Thus, the literature suggests the need of an intervention or a new ergonomically designed spike shoe.

The gastrocnemius muscle controls foot motion in response to PF and foot pronation [12,13]. Running shoes should possess a heel wedge in order to reduce Achilles tendon stretch. Plantar fasciitis, also common among track-and-field runners, represents an inflammation of the plantar fascia, due to abnormal pronation.

TA fatigue is attributable to more than just metabolic change or cost [16]. Research finds that differences of foot angle when switching from PF (running) to walking tends to affect the intensity of TA activity. Track athletes experience forces of impact ranging between 1.0 and 2.5 times their body weight during running [5]. Running constitutes a great effort on muscles in the lower extremities; this effect could benefit from after-running support to absorb and relieve these muscles from heel impact during walking. In addition, the authors apply the term "muscle tuning" to refer to the muscular tendency to adopt an activation pattern. Muscles become acclimated to behaving a certain way during a specific activity. A transition to another activity increases muscle effort, sometimes triggering fatigue. In the case of the transition from running to walking, the literature suggests that "a reduction of muscle activity before heel strike is associated with fatigue" [5]. Since walking implies a reduction of muscle activity from running, it may be deducted that a decrease in locomotion speed (transitioning from running to 
walking) can also trigger fatigue due to the effort of retreating from the previous "muscle tuning" experienced during running.

The concept or removable heels has been adapted in various areas, including bowling, basketball, and ladies' high heel shoes. In this project, allowing a runner's feet to remain at an even level with removable heels helps avoid an excessive upward flexion of the foot as the runner walks before and after a practice or competition. Research regarding Nike spike shoes in measurements with and without the removable heel indicates that the regular spike shoe elevates the toes and the front half of the foot [3]. Such elevation alters phases 2 and 3 of the walking stance, while it increases the angle of the toes to approximately 25 degrees. On the other hand, when wearing spike shoes with a removable heel, the toes are still slightly elevated. Yet as the heel restores the balance lost to this elevation, the elevation becomes about 10 degrees less than when the heel is not present. Therefore, the Achilles tendon stretch and the stress level on the extrinsic foot muscles are likely to be reduced in phases 2 and 3 . Actually, when wearing the heel, only phase 2 differs from normal walking after balance is restored.

The shoes presented in Figures 1 and 2 are used by mid-distance and short distance runners when walking to and from practice or competition.

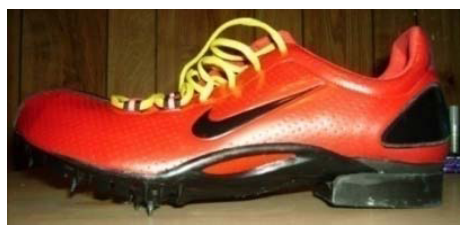

Figure 1: Spike shoe with removable heel - side view

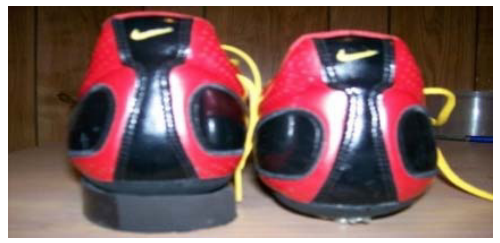

Figure 2: Spike shoes: heel vs. no heel - rear view

\section{Methods and procedures}

\subsection{Participants}

Nine healthy participants were selected: 3 long and mid-distance runners (males), 3 sprinters (males), and 3 non-athlete subjects who exercise regularly ( 2 males, 1 female). The average age of participants was 25.2 years (SD 3.07), their mean stature was $175.0 \mathrm{~cm}$ (SD 7.11), and the average of body mass was $80.5 \mathrm{~kg}$ (SD 6.5).

\subsection{Task design}

The participants walked on a treadmill (Nautilus T914 Commercial Treadmill), wearing the original shoes for one session and the biomechanically modified shoes for a second comparative session. The treadmill was set to 2 $\mathrm{mph}$ and $3 \mathrm{mph}$, speeds at which athletes are generally comfortable with [21], while the EMG apparatus was set to measure specific muscle activity in all sessions. A surface EMG with a lightweight, wireless, battery-operated device with transmission up to $250 \mathrm{~m}$ was used (Myomonitor IV Wireless Transmission and Datalogging system by Delsys) [6].

To evaluate muscle activity, fatigue, and stress during the entire duration of the exercise, EMG pads were placed on the participant's left TA and the left medial gastrocnemius.

A rubber heel compatible with a size 10 Nike pair of spikes, was designed and built. Velcro fabric was attached to the sole of the spike and the top of the removable heel, while holes were drilled to fit with the spikes' screws. 
After each test, participants were also asked to rate the level of pain / discomfort they felt on areas 20 to 27 (knees, calves, ankles, and feet) of the body map (Figure 3). Discomfort/pain is expressed on the standard ergonomics scale established by Borg's category-ratio scale (CR-10), where $0=$ no pain at all, and $10=$ absolutely unbearable.

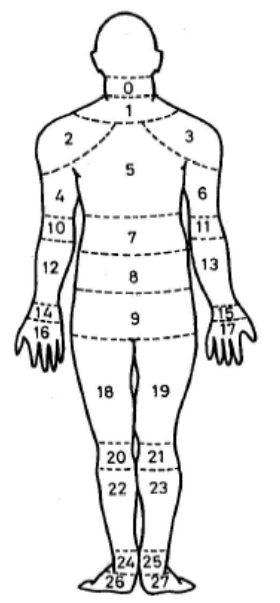

Figure 3: Body map sections [10]

\subsection{Statistical Analysis}

A two-factor repeated measures analysis of variance (ANOVA) was performed to determine the effect of the removable heel and speed on the normalized EMG activity of the tibialis and gastrocnemius muscles. Also, a singlefactor repeated measures ANOVA was performed to determine the removable heel effect on the subjective discomfort ratings. The significance level was set at 5\% for the statistical tests. Software Statistix 9.0 and SAS 9.1 were used for the analysis.

\section{Results}

\subsection{EMG}

The EMG activity of both extrinsic foot muscles decreased when using the removable heel. Figure 4 shows that at $2 \mathrm{mph}$ the EMG activity of the TA and gastrocnemius decreased by $21.5 \%$ and $23.5 \%$, respectively, from walking without the heels to walking with the heels. Figure 5 shows that adding the heel, during the 3 mph experiment, decreased the muscle activity by an average of $22.5 \%$ in the TA and $25 \%$ in the gastrocnemius. All participants experienced an activity decrease in the TA and gastrocnemius during both walking experiments when the heel was added. 


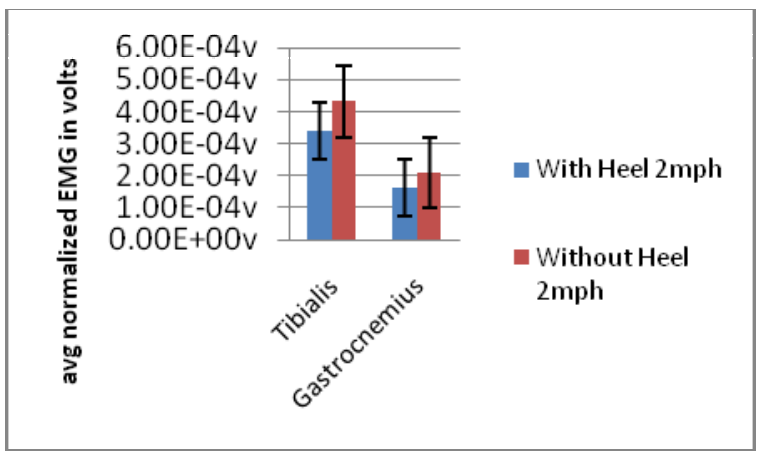

Figure 4: EMG results at $2 \mathrm{mph}$

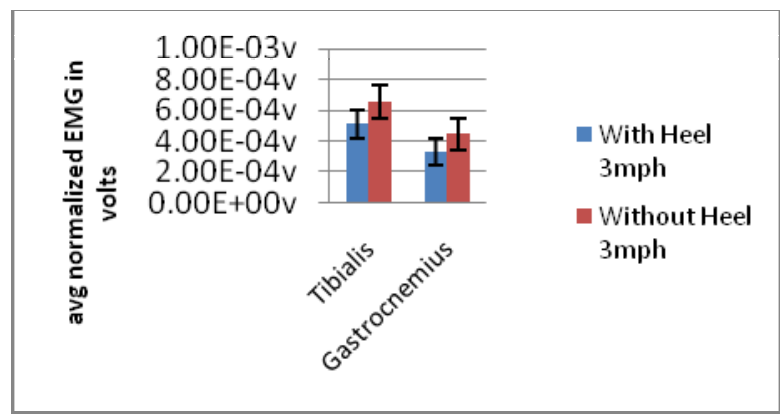

Figure 5: EMG results at $3 \mathrm{mph}$

While trained sprinters are accustomed to practicing in spikes without heels, practicing on the toes remains harder for distance runners; during regular practice, distance runners must use their heels more than sprinters. The differences between activity with and without heel were averaged for each athletic background. Table1 summarizes the average percent decrease in muscle activity from walking without heels to walking with heels. Figures 6 and 7 show bar graphs of the percent decrease in EMG activity for the TA and gastrocnemius muscles, respectively.

Table 1: Percent average of muscle activity decrease from walking without heels to walking with heels

\begin{tabular}{|lllll|}
\hline $\begin{array}{l}\text { Area and speed } \\
\text { in miles per hour } \\
(\mathrm{mph})\end{array}$ & $\begin{array}{l}\text { Sprint } \\
\text { runners }\end{array}$ & $\begin{array}{l}\text { Distance } \\
\text { runners }\end{array}$ & $\begin{array}{l}\text { Non- } \\
\text { athletes }\end{array}$ & Average \\
\hline Tibialis $-2 \mathrm{mph}$ & $21 \%$ & $23 \%$ & $25 \%$ & $23 \%$ \\
\hline Tibialis - $3 \mathrm{mph}$ & $20 \%$ & $22 \%$ & $24 \%$ & $22 \%$ \\
\hline Average & $20 \%$ & $23 \%$ & $24 \%$ & $22 \%$ \\
\hline $\begin{array}{l}\text { Gastrocnemius }- \\
2 \text { mph }\end{array}$ & $19 \%$ & $24 \%$ & $32 \%$ & $25 \%$ \\
\hline $\begin{array}{l}\text { Gastrocnemius }- \\
3 \text { mph }\end{array}$ & $21 \%$ & $25 \%$ & $34 \%$ & $27 \%$ \\
\hline Average & $20 \%$ & $25 \%$ & $33 \%$ & $26 \%$ \\
\hline
\end{tabular}

Among athletes, the heel benefits distance runners the most. This is due to the fact that this group of runners consistently performs in DF and therefore needs extra support in the heels. The spikes, in sole performance, cannot provide such support without the removable heel. Observations of different running gaits provide insights toward understanding the discrepancy of result values between participants of different backgrounds [20]. Long and mid-distance runners tend to have both heels and forefeet striking the ground simultaneously at the beginning of the contact stage of stance. On the other hand, sprint runners' forefeet mostly present the only contact with the 
ground throughout the stance phase [20]. The following diagrams illustrate this fact more by emphasizing the contrast between the athletic backgrounds:

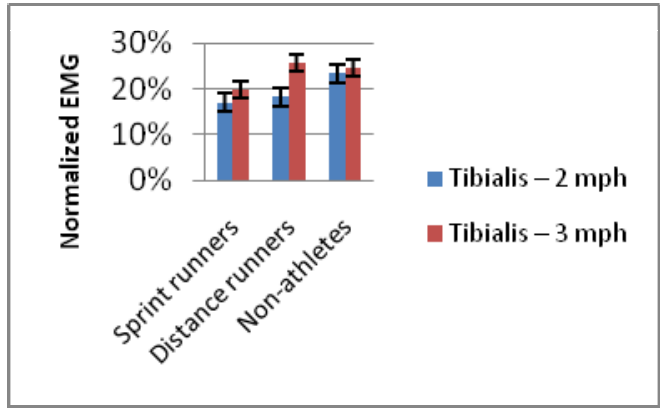

Figure 6: Percent decrease in TA activity for each participant group

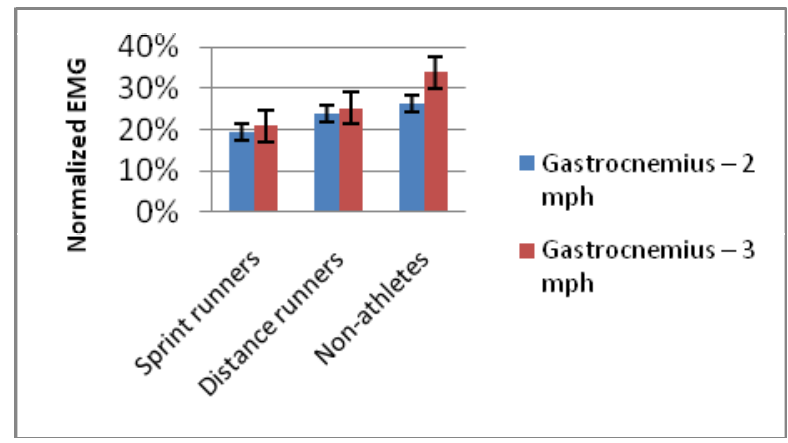

Figure 7: Percent decrease in gastrocnemius activity for each participant group

Table 2: ANOVA results

\begin{tabular}{|c|c|c|}
\cline { 3 - 3 } \multicolumn{2}{c|}{} & \multicolumn{1}{c|}{ p-value } \\
\hline \multirow{4}{*}{ Tibialis } & Heel & 0.0005 \\
\cline { 2 - 3 } & Speed & 0.001 \\
\cline { 2 - 3 } & Heel*Speed & 0.473 \\
\hline \multirow{3}{*}{$\begin{array}{c}\text { Gastrocne- } \\
\text { mius }\end{array}$} & Heel & 0.0012 \\
\cline { 2 - 3 } & Speed & 0.0006 \\
\cline { 2 - 3 } & Heel*Speed & 0.0583 \\
\hline
\end{tabular}

Table 2 contains the EMG results of ANOVA. The ANOVA test shows a significant difference between the muscle activities without heel and with heel at 2 and $3 \mathrm{mph}$. This outcome reveals that wearing the removable heel reduces the muscle activity at both the gastrocnemius and TA.

The speed factor impacts the activity level for both muscles as indicated by the palues of 0.0006 and 0.0010 for the gastrocnemius and the TA, respectively. A change of speed from $2 \mathrm{mph}$ to $3 \mathrm{mph}$ is associated with significant change in muscle activity, whether walking with heels or without. 
It shows that the interaction effect of speed and the removable heels were not statistically significant; the pvalue of the interaction effect was 0.0583 for the gastrocnemius muscle and 0.4739 for the tibialis muscle. This means that the effect of speed and the removable heels on the EMG readings are independent of each other.

\subsection{Body discomfort}

The perceived discomfort results have similar findings to the EMG results. The discomfort ratings for areas 20 to 27 of the body map (Figure 3) decreased when using the removable heels. Table 3 shows the average discomfort ratings for all body areas, and Figure 8 is a bar graph representation of Table 3

Table 3: Averaged discomfort values before and after heel installation

\begin{tabular}{|llll|}
\hline & $\begin{array}{l}\text { Before heel } \\
\text { installation }\end{array}$ & $\begin{array}{l}\text { After heel } \\
\text { installation }\end{array}$ & $\begin{array}{l}\text { Discomfort } \\
\text { decrease }\end{array}$ \\
\hline Area 20-21 (knees) & 5.2778 & 2.6111 & 2.6667 \\
Area 22-23 (calves) & 5.2222 & 2.6111 & 2.6111 \\
Area 24-25 (ankles) & 6.7778 & 2.8889 & 3.8889 \\
Area 26-27 (feet) & 6.7778 & 2.2778 & 4.5 \\
\hline
\end{tabular}

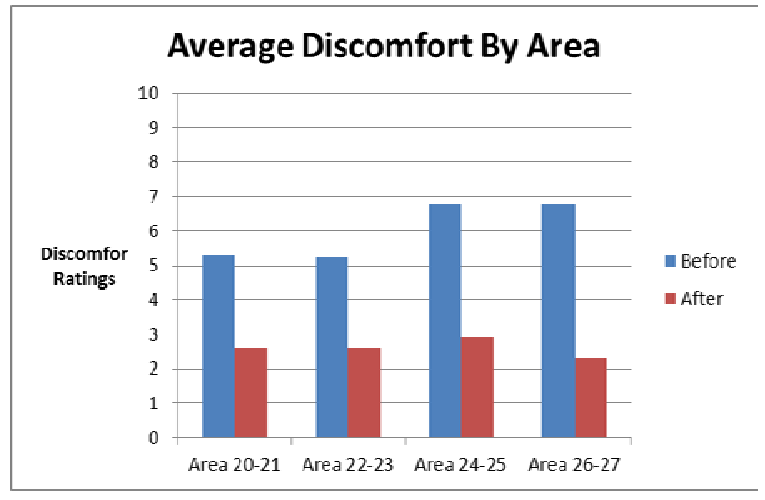

Figure 8: Graphed ANOVA results by area

Table 4 shows that non-athletes reported the greatest relief from the removable heel in all areas with the exception of the calves. However, this is the same area in which distance runners experienced the greatest relief. Indeed, participants with a lack of athletic experience in track need more leg support, owing to the unfamiliarity with walking in spike shoes. Sprinters experienced the least relief from the removable heel, even though the biomechanical modification was designed especially for this target group. Sprinters are most accustomed to walking in spike shoes.

Table 4: Average discomfort difference by participant category

\begin{tabular}{|llll|}
\hline Body Map Area & $\begin{array}{l}\text { Non- } \\
\text { athletes }\end{array}$ & $\begin{array}{l}\text { Distance } \\
\text { runners }\end{array}$ & $\begin{array}{l}\text { Sprint } \\
\text { runners }\end{array}$ \\
\hline Area 20-21 (knees) & 3 & 3 & 2 \\
Area 22-23 (calves) & 2.7 & 3.8 & 1.3 \\
Area 24-25 (ankles) & 4.5 & 4.2 & 3 \\
Area 26-27 (feet) & 5 & 4.2 & 3.5 \\
\hline
\end{tabular}




\section{Implications}

The shoe was tested on a limited number of participants. Also, this study does not provide results for the scope of pain felt by subjects due to individual gait, bone structure, weight, height, age, running experience, or gender. Furthermore, only one prototype - size 10 - was available. This limited the number of participants for the experiment, especially in terms of trained athletes. To further increase the external validity of this research, the following conditions can be considered:

- Allow the participants to run at their speed of choice, that is, the same speed used on the track before wearing the heel

- Make the session longer than one minute

- Place electrodes on both legs to ensure accuracy of muscle activity data

- Select more trained subjects, males and females

Sliding instead of screwing the heel to the sole might be a faster attaching mechanism. A follow-up study to this research could measure how much intensity is absorbed when the removable heel is applied, and quantify the heel's ergonomic worth and value. As a whole, the project successfully provides an analytical basis for a product ergonomic in design for the track athlete.

\section{References}

[1] A.C. McGrath and C.F. Finch, Running the race against injuries: a review of the literature, Monash University Accident Research Centre, Victoria, Australia, 1996.

[2] A.E. Hunt, R.M. Smith, M. Torode, Extrinsic muscle activity, foot motion and ankle-joint moments during the stance phase of walking, Foot Ankle International, Lidcombe, Australia, 2001, 543.

[3] A.S. Alangari, Biomechanics of sport's shoes, 9th Congress of Asian Federation of Sports Medicine. Riyadh, Saudi Arabia, 2006.

[4] B.G. Donley and M. Leyes, Anterior Bony Ankle Impingement, Operative Techniques in Sports Medicine 9 (2001), 2-7.

[5] B.M. Nigg, D. Stefanyshyn, G. Cole, P. Stergiou, J. Miller, The effect of material characteristics of shoe soles on muscle activation and energy aspects during running, Journal of Biomechanics 36 (2003), 569-575.

[6] Delsys, Inc. "Myomonitor IV EMG System User's Guide". Boston, MA. 2009.

[7] G.J. Tortora, Principles of Human Anatomy, John Wiley and Sons, Inc., ed., New York, 2002.

[8] J.B. Saunders, V.T. Inman, and H.D. Eberhart, The major determinants in normal and pathological gait, Journal of Bone and Joint Surgery 35A (1953), 543-558.

[9] J.M. Wakeling, V. Tscharner, B.M. Nigg, and P. Sergiou, Muscle activity in the leg is tuned in response to ground reaction forces, Journal of Applied Physiology 91.3, (2001), 1307-1317.

[10]J.R. Wilson and E. N. Corlett. Evaluation of Human Work: A Practical Ergonomics Methodology, Taylor and Francis, ed., Pennsylvania, 1995, 686-687.

[11] K.H. Myburgh, N. Grobler, and T.D. Noakes, Factors associated with shin soreness in athletes, The Physician and Sportsmedicine, 1988.

[12] K.M. O'Connor and J. Hamill, The role of selected extrinsic foot muscles during running, Clinical Biomechanics 19 (2004), $71-77$.

[13] K.M. O'Connor, J. Hamill, and T.B. Price, Thomas B, Examination of extrinsic foot muscles during running using mfMRI and EMG, Journal of Electromyography and Kinesiology (2006), 522-530.

[14] K.S. Lee, A.M. Waikar, F. Aghazadeh, and S. Tandon, An electromyographic investigation of neck angles for microscopists 30 (1986), 548-551.

[15]L. Reber, J. Perry, M. Pink, Marilyn, Muscular control of the ankle in running, American Journal of Sports Medicine 21 (1993), 805-810.

[16]L. Segers, Aerts, and De Clercq. EMG Measurements, Department of Movement and Sport Sciences, Ghent University. Ghent, Belgium, 2006.

[17] M. Elliott, Personal Interview, Louisiana State University, 2007.

[18] M. Elliott, Personal Interview, Louisiana State University, 2008.

[19] M. Solomonow, S. Hatipkarasulu, B.H. Zhou, R.V. Baratta, and F. Aghazadeh, Biomechanics and electromyography of a common idiopathic low back disorder, Spine 28.12 (2003), 1235-1248.

[20]P. Brukner, K. Khan, and J. Kron, The Encyclopedia of Exercise, Sport, and Health, ed., Allen \& Unwin, Australia, 2004.

[21] S.K. Au; P. Dilworth, and H. Herr, An ankle-foot emulation system for the study of human biomechanics. Proceedings of the 2006 IEEE International Conference on Robotics and Automation, Florida, 2006. 